\title{
Endovascular Treatment of Pulmonary Arteriovenous Malformations: How We Do It
}

\begin{abstract}
Pulmonary arteriovenous malformation (PAVM) is a rare disease disproportionally affecting patients with hereditary hemorrhagic telangiectasia and may be associated with other pulmonary or infectious etiologies. Respiratory symptoms are the most common, including dyspnea, hypoxemia, and hemoptysis. Due to the impairment of normal pulmonary filtration function, patients with PAVM are at risk for embolic events, ranging from ischemic strokes to brain abscesses. More importantly, PAVM can enlarge over time or with physiological changes, which may lead to catastrophic hemorrhages and increased embolization risks. From imaging perspective, echocardiography with contrast bubbles and computed tomography can both be used to diagnose PAVMs with high sensitivity and specificity. Treatment modalities have evolved from invasive surgeries to transluminal catheter-based interventions. In recent decades, the evolution of interventional techniques and equipment has resulted in a high technical success rate for the treatment of PAVMs. Here, we present the interventional PAVM treatment protocol at our institution.
\end{abstract}

Keywords: Interventional treatment, multidetector computed tomography, pulmonary arteriovenous malformation, transthoracic contrast echocardiography

\section{Introduction}

Pulmonary arteriovenous malformations (PAVMs) are abnormal vascular connections most commonly between the pulmonary arteries and veins. The aberrant connection bypasses the capillary bed, thereby creating an anatomical right-to-left shunt. The first PAVM was reported in 1897 through the autopsy of a 12-year-old boy. ${ }^{[1]}$ The advent of noninvasive imaging, particularly computed tomography (CT), has shed light on the true prevalence, which was estimated to be 38 cases per 100,000 individuals in one study. ${ }^{[2]}$ PAVM-related symptoms manifest between the fourth and sixth decades with female predominance. ${ }^{[3]}$ The majority of PAVMs occur in patients suffering from hereditary hemorrhagic telangiectasia (HHT), accounting for approximately $90 \%$ of PAVM cases. Multiple studies have shown that HHT patients have a PAVM incidence of $18 \%-58 \%$ depending on the genotypes of HHT. ${ }^{[4,5]}$ Sporadic PAVM can be associated with liver cirrhosis, infection, trauma, Fanconi syndrome, hepatopulmonary syndrome, or bidirectional cavopulmonary

This is an open access journal, and articles are distributed under the terms of the Creative Commons AttributionNonCommercial-ShareAlike 4.0 License, which allows others to remix, tweak, and build upon the work non-commercially, as long as appropriate credit is given and the new creations are licensed under the identical terms.

For reprints contact: reprints@medknow.com shunts. ${ }^{[6,7]}$ PAVMs can result in a host of complications, ranging from systemic hypoxemia and neurological manifestations to life-threatening hemorrhage. The therapeutic options for PAVM have evolved from lobectomy and segmentectomy to percutaneous transcatheter interventions. In this article, we review the common clinical manifestations, diagnostic imaging, and therapeutic options of PAVM. We also present our institutional approach on the endovascular treatment of PAVM.

\section{Clinical Manifestations}

PAVM can manifest in simple or complex forms. Simple PAVM typically has a single feeding artery and draining vein, while a complex PAVM has multiple feeding arteries [Figures 1-3]. Diffuse PAVMs are rare, affecting approximately $7 \%-11 \%$ of the PAVM patient population and present as numerous small aneurysmal sacs in multiple segmental branches. ${ }^{[8]}$ Feeding and draining vessels are typically pulmonary arteries and veins. However, in certain cases, systemic connections may occur through a feeding bronchial artery or a direct draining vein into the inferior vena cava or innominate vein. PAVM is typically located in the inferior segments and can

How to cite this article: Li X, Alkukhun L, Partovi S, Kondray V, Al-Natour M. Endovascular treatment of pulmonary arteriovenous malformations: How we do it. Arab J Intervent Radiol 2018;2:64-70.

\section{Xin Li, Leen Alkukhun, Sasan Partovi ${ }^{1}$, Victor Kondray, Mohammed Al-Natour}

Department of Radiology, University Hospital Cleveland Medical Center, Case Western Reserve University, 'Department of Interventional Radiology, Cleveland Clinic, Cleveland, Ohio, USA

Address for correspondence Mohammed Al-Natour, MD, Department of Radiology, University Hospital Cleveland Medical Center, Case Western Reserve University, Cleveland, Ohio, USA.

E-mail:mnatour85@msn.com

Access this article online Website: www.arabjir.com DOI: 10.4103/AJIR.AJIR_23_18 Quick Response Code:

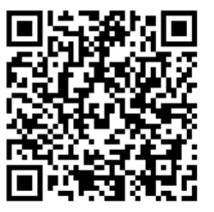




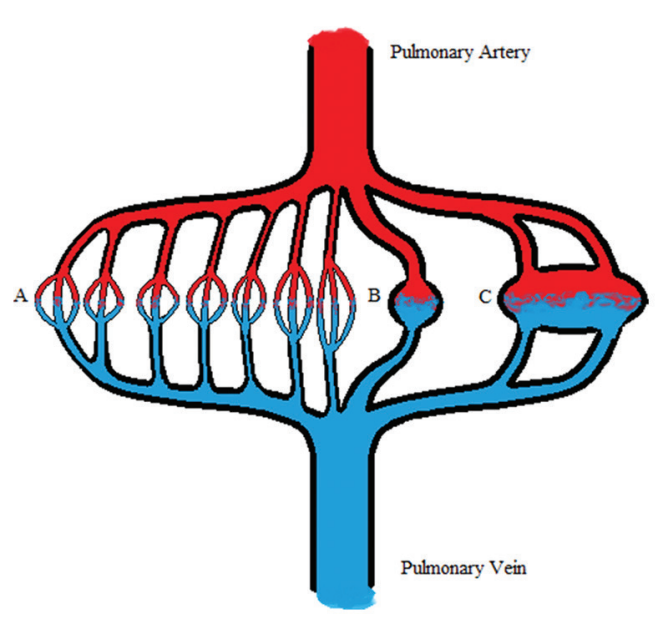

Figure 1: Schematic diagram of the pulmonary arteriovenous malformation. "A" represents the normal pulmonary capillary bed. "B" represents a simple pulmonary arteriovenous malformation with a single feeding artery and drainage vein. A complex pulmonary arteriovenous malformation is illustrated by "C" with multiple feeding arteries and drainage venous vasculature

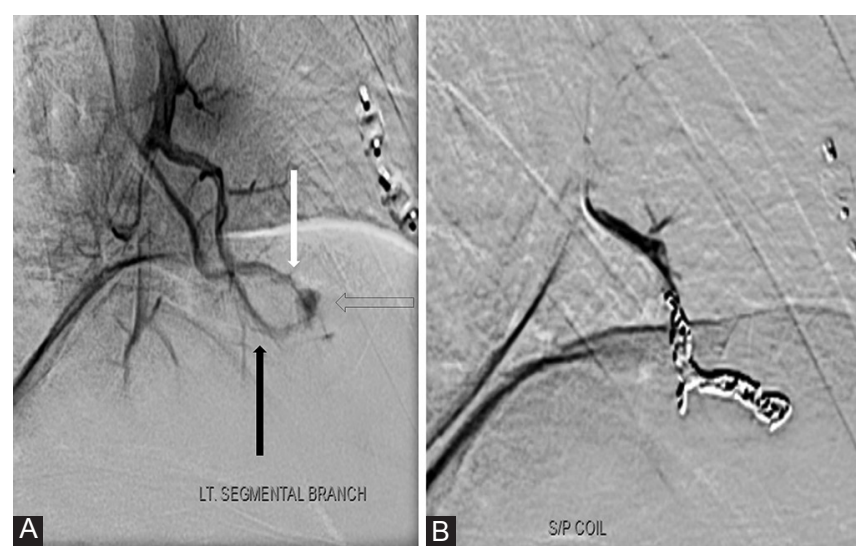

Figure 2: Single pulmonary arteriovenous malformation. Panel A shows a simple pulmonary arteriovenous malformation. Notice the single feeding and draining vessel (white and black arrows, respectively). Also note the aneurysmal shape of the abnormal arteriovenous connection (hollow arrow). Panel B shows the postembolization angiography of the same simple arteriovenous malformation, notice the absence of abnormal arteriovenous connection

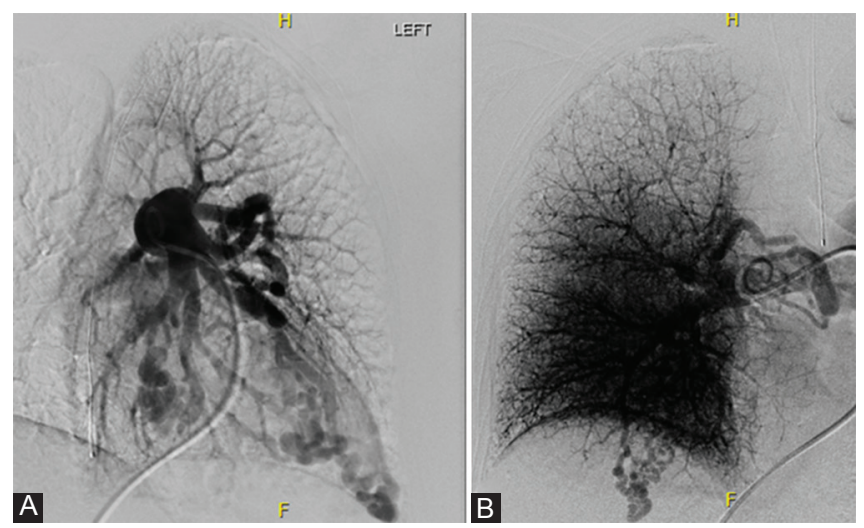

Figure 3: A hereditary hemorrhagic telangiectasia patient with multiple bilateral pulmonary arteriovenous malformations. Panel A demonstrates multiple pulmonary arteriovenous malformations in the left lower lobe. Note the tortuosity of the feeding vessels. Panel B reveals multiple pulmonary arteriovenous malformations in the right lower lobe manifest bilaterally. In HHT patients, 69\% of PAVMs are located in the lower lobes. Histologically, PAVM is composed of a thin-walled aneurysmal sac with a single layer of endothelium..$^{[9]}$

A single PAVM with an aneurysmal diameter $<2 \mathrm{~cm}$ does not cause significant symptoms. ${ }^{[10]}$ In fact, the majority of PAVM patients may be asymptomatic. In a study of 305 patients, $79.5 \%$ of the patients did not experience significant clinical symptoms and were diagnosed incidentally. ${ }^{[1]}$ Patients suffering from bilateral diseases and multiple PAVMs are more likely to present earlier with more severe symptoms. Respiratory manifestations are the most common, owing to the anatomical shunt created by the PAVM. Asymptomatic hypoxemia is a common clinical presentation, with resting oxygen saturations as low as $78.5 \%$. Remarkably, patients were able to pursue strenuous activities with a low resting oxygen saturation due to compensatory hematological responses. Studies have shown that there was an increase of hemoglobin by $0.82 \mathrm{~g} / \mathrm{dl}$ for every $1 \%$ fall in resting oxygen saturation in the PAVM population. ${ }^{[12]}$ In addition, PAVM patients had higher resting and exercise cardiac output and maintained good maximum exercise capacity despite the profound decrease in arterial oxygen saturation during the exercise. ${ }^{[13]}$ In addition, PAVM patients may present with symptomatic dyspnea at rest. In a review of more than 1000 patients, the prevalence of dyspnea was $44 \%$ among HHT patients with PAVM. In addition, the odds ratio for dyspnea among HHT patients with and without PAVM was 3.45..$^{[14]}$ More interestingly, since the majority of PAVM is located in the lower lung segments, patients may experience orthodeoxia (increased dyspnea upon standing) and platypnea (relief of dyspnea upon lying down). The dependent perfusion of PAVM increases with gravity, thereby exacerbating the right-to-left shunt. Conversely, resuming a supine position leads to the re-distribution of blood flow into the upper lobes where PAVMs are less abundant, thereby increasing the ventilation/perfusion ratio. Other respiratory signs and symptoms may include cyanosis and clubbing of the digits.

Apart from the physiological shunt, the thin-walled aneurysmal sac carries a small risk of rupture. It is a relatively rare phenomenon, since PAVM is perfused by the low-pressure system of the pulmonary circuit. However, if the PAVM is perfused by the systemic circulation, i.e., the bronchial artery, the risk of bleeding is higher. Patient may then present with hemoptysis and hemothorax. ${ }^{[15,16]}$ In addition, pregnancy carries a significantly higher risk of PAVM hemorrhage likely attributed to the increased cardiac output and blood volume during pregnancy. It is worth noting that PAVMs often increase in size and number during the pregnancy. In a retrospective review, the risk of PAVM hemorrhage during pregnancy and delivery was $1.4 \%$, while the risk during the postpartum period was $0.6 \% .{ }^{[17]}$ 
The pulmonary circuit serves as a filter for the systemic circulation. The compromised filtration function puts patients at higher risk of paradoxical emboli of both infectious and embolic etiologies. Cerebral abscess affects $7.8 \%-12.8 \%$ of the patients. ${ }^{[11,18]}$ In addition, the incidence of cerebral abscess is 155 cases per 100,000 individuals per year in HHT patients, while the rate is 0.4 cases per 100,000 individuals per year in the general population. ${ }^{[8]}$ The risk of cerebral abscess formation has been directly related to the number of PAVMs (11.5 vs. 6.2 untreated PAVMs in patients with and without brain abscess), while the risk for strokes has been directly related to the size of the feeding artery $(4.9 \mathrm{~mm}$ vs. $3.2 \mathrm{~mm}$ in patients with and without ischemic stroke). ${ }^{[19]}$ Embolic events can lead to transient ischemic attack or ischemic stroke. In one study, $33 \%$ of PAVM patients suffered from an ischemic stroke while $18 \%$ endured a transient ischemic attack. ${ }^{[20]}$ The risk of ischemic stroke decreases after endovascular treatment of PAVMs.

\section{Imaging Diagnosis}

Due to the high incidence of PAVMs in HHT patients and the significant morbidity and mortality, screening for PAVMs in patients with HHT is warranted. Transthoracic contrast echocardiography (TTCE) has become the initial screening modality for PAVMs due to its high sensitivity and negative predictive value. On TTCE, agitated saline is injected while the heart is monitored on the four-window view. In a normal individual, gas rapidly diffuses down the concentration gradient in the pulmonary capillary. Therefore, saline bubbles quickly shrink and rupture. On the contrary, in a PAVM patient, saline bubbles will not undergo destruction due to the right-to-left shunt. Therefore, the TTCE test is considered positive if saline bubbles are visualized in the left chambers [Figure 4]. To differentiate between cardiac and pulmonary shunts, contrast bubble visualization after four cardiac cycles is considered positive for a pulmonary shunt. TTCE can be used to assess the right-to-left shunt size as well. ${ }^{[2]]}$ One to 29 bubbles were indicative of a grade 1 shunt, while 30 to 100 bubbles and more than 100 bubbles were considered positive for grade 2 and 3 shunts, respectively. ${ }^{[21,22]}$ Grade 3 shunts have a $92.5 \%$
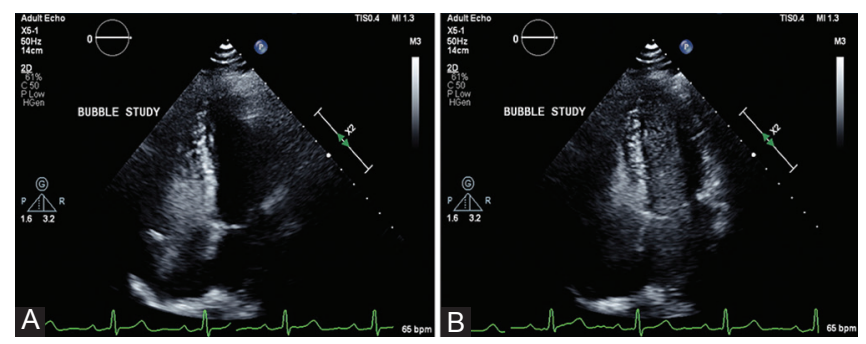

Figure 4: Transthoracic contrast echocardiography. Panel A shows enhancement in the right atrium, representing contrast saline bubbles. Panel B shows enhancement in both left and right atria, indicative of an underlying shunt. The bilateral enhancement may also indicate a severe right-to-left shunt positive predictive value for PAVM detectable on $\mathrm{CT}$ angiography. ${ }^{[23]}$

HHT patients with negative initial TTCE should undergo repeated testing every 5 to 10 years. Repeated screening should also be considered after puberty and before pregnancy due to the increased risk of PAVM enlargement during this period. ${ }^{[24]}$ Patients with positive TTCE should be evaluated with $\mathrm{CT}$ angiography as the noninvasive modality of choice. CT can demonstrate the size and location of the PAVM for treatment planning purposes. On CT imaging, a simple PAVM appears as a well-defined peripheral nodule with a clear feeding artery and drainage vein. ${ }^{[25]}$ In comparison, a complex PAVM will show multiple feeding and drainage vessels on CT. The emphasis is on the visualization of both feeding and drainage vessels since other pulmonary process, such as granuloma, can resemble the appearance of PAVM [Figure 5]. ${ }^{[26,27]}$ If $\mathrm{CT}$ scan appears to be normal, repeat $\mathrm{CT}$ scan may be considered at 6-12 months after the initial scan in high-risk population such as HHT patients. ${ }^{[23]}$ It is worth noting that there is no consensus guideline on diagnosing and treating PAVM, clinical practice varies widely among institutions. ${ }^{[28]}$

Catheter-directed angiography may also serve to diagnose and treat PAVM. Until recently, invasive angiography was the gold standard for evaluating the pulmonary arterial system. Angiogram follow-up may also be necessary to assess treatment response and need for further endovascular treatment sessions. ${ }^{[23,29]}$ Other imaging modalities include perfusion scan, although it has largely been replaced by the state-of-the-art CT and magnetic resonance imaging imaging for both morphological and perfusion assessment. Perfusion scan may still have a role in assessing shunt ratio in the correct clinical context $^{[30]}$ [Figure 6].

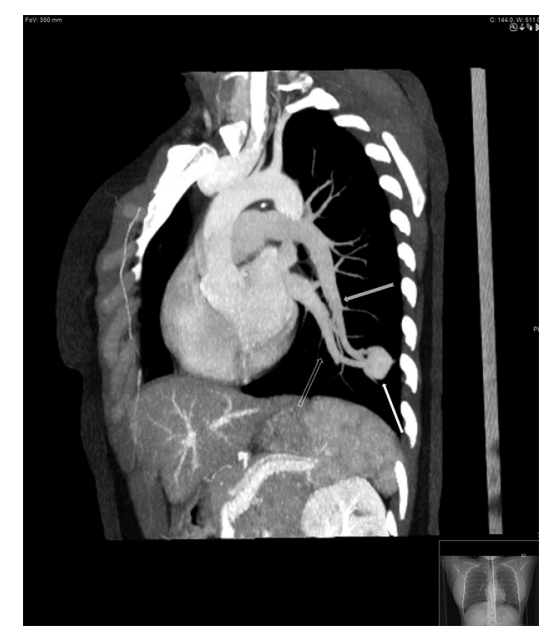

Figure 5: Maximum intensity projection of a computed tomography image of a simple pulmonary arteriovenous malformation. Note the single feeding artery (notched arrow), draining vein (hollow arrow), and aneurysmal fistulous communication sac (white arrow). Image courtesy of Dr. Amit Gupta, MD 


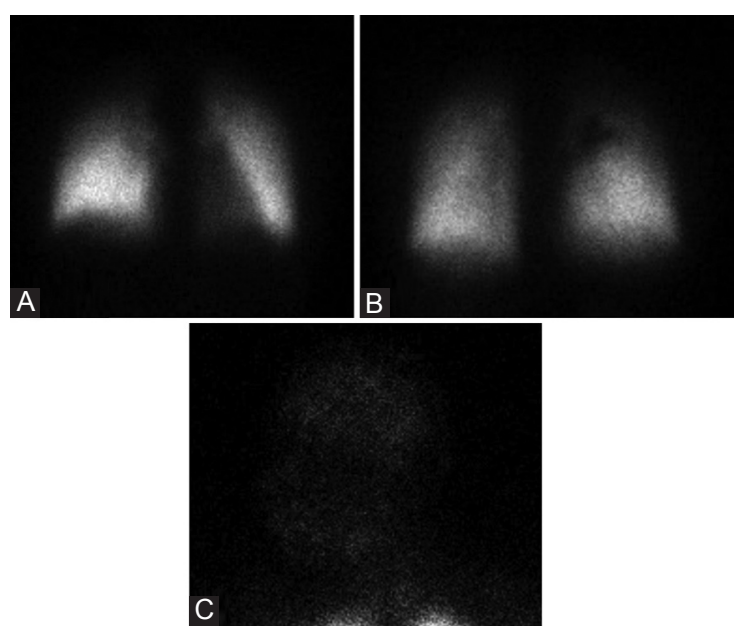

Figure 6: Perfusion lung scan. Panels A and B show several perfusion defects in the bilateral upper lobes. Panel $\mathrm{C}$ depicts abnormal radiotracer uptake, indicating an underlying right-to-left shunt. In this patient, the shunt is caused by the bilateral pulmonary arteriovenous malformations. This particular patient has undergone previous embolization for pulmonary arteriovenous malformation. Recanalization was suspected and perfusion scan confirmed the recanalized pulmonary arteriovenous malformation by demonstrating abnormal right-to-left shunt

\section{Treatment of Pulmonary Arteriovenous Malformations}

From the 1940 s to 1970 s, surgery used to be the only treatment option for PAVM. Ligation, segmentectomy, lobectomy, and pneumonectomy were performed. The postoperative PAVM recurrence rate was low. In a small case series, nine patients underwent surgical excision of PAVMs. At a mean follow-up period of 12 years, none of the patients experienced recurrence. ${ }^{[31]}$ Lung transplantation is a last resort option for patients who are suffering from diffuse, bilateral diseases. ${ }^{[32]}$

Apart from surgery, transcatheter embolization enables minimally invasive management of PAVM. In 1977, the first embolization procedure using steel coils for the treatment of PAVM was performed. ${ }^{[33]}$ Since then, transcatheter embolization has gradually become the mainstay treatment option. Surgery is now reserved for patients with failed embolization or life-threatening hemorrhage. The goal of embolization is to embolize the fistula close to, or at the junction of the feeding artery and the aneurysm. ${ }^{[6]}$ Historically, a $3-\mathrm{mm}$ feeding artery was thought to be a significant risk factor for paradoxical embolization and was chosen as the threshold indication for interventional treatment. However, evidence has shown that as high as $13.5 \%$ of the patients with untreated below-threshold PAVM suffered from paradoxical embolization as well. ${ }^{[11,34,35]}$ Further, case reports have shown that untreated PAVM could gradually grow in size. ${ }^{[36]}$ Therefore, interventional therapy may be considered in feeding arteries $<3 \mathrm{~mm}$ if subselection is technically feasible. Different strategies, techniques, and embolizing agents have been described, such as detachable balloons,
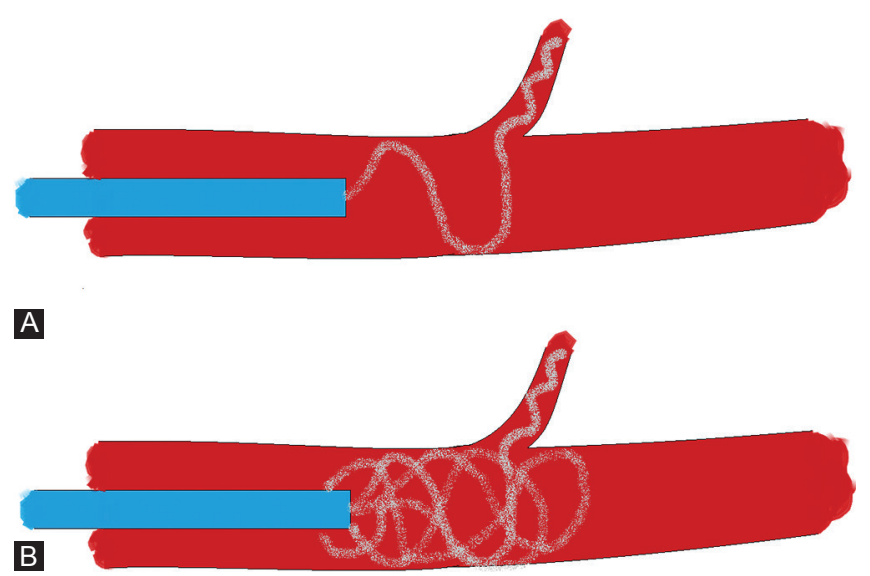

Figure 7: Anchoring techniques. Catheter may advance toward a side branch of the feeding artery. The $1^{\text {st }}$ or $2 \mathrm{~cm}$ of the coil may be anchored in the small feeling artery. Then, the catheter can be pulled back and the rest of the coil deployed in the main feeding artery

pushable fibered coils, vascular plugs, and detachable coils. Here, we would like to present the PAVM protocol at our institution.

\section{How We Do It}

In some other institutions, interventional radiologists advocate giving a $3000-5000 \mathrm{U}$ of heparin bolus after the catheter introduction as a safety measure against thrombus formation in or around the catheter, eventually preventing inadvertent paradoxical thromboembolism. We personally elect not to heparinize patients because $67 \%-83 \%$ of HHT patients also have telangiectasia in the oral or nasal mucosa and lips. Giving heparin might provoke nasal and/or oral bleeding which could compromise the airway.

All catheter and guidewire manipulations or exchanges should be performed in a manner that prevents air from entering the catheter, causing inadvertent air embolism across the PAVMs. Our preferred method to address this issue is to perform all exchanges and catheter manipulations while the catheter hub is submerged in a saline-filled bowl. In addition, frequent catheter flushing with bubble-free solution is a critical technique in this procedure.

We usually perform PAVM embolization procedures through a right common femoral vein approach under moderate sedation and local anesthesia, which results in increased stability for embolization. It is worth mentioning that oversedation should be avoided since patient cooperation and respiratory maneuvers are imperative for adequate imaging and treatment planning. In addition, patients with PAVMs are generally young and nervous about their diagnosis which can lead to a hyperdynamic state. Pulmonary angiography in this population may require higher flow rates $(30-35 \mathrm{ml} / \mathrm{s}$ for $2 \mathrm{~s})$ than the typical older patients with thromboembolic disease.

We usually place a $9 \mathrm{Fr}$ short vascular sheath in the right common femoral vein. Then, we place a pulmonary 
angiographic catheter coaxially through the sheath over a guidewire. Our preferred method to select the pulmonary artery is by using a $7 \mathrm{Fr}$ pulmonary angiographic catheter to allow for high-contrast injection rates (i.e. $>20-25 \mathrm{ml} / \mathrm{s}$ ). The most used catheter is the Grollman pulmonary artery catheter (Cook Inc., Bloomington, IN, USA). Such catheter usually has a preformed pigtail and a $90^{\circ}$ reversed secondary curve $3 \mathrm{~cm}$ proximal to the pigtail. The pigtail catheter is placed in the right atrium. The anteromedial portion of the right atrium is probed to facilitate catheter entry into the right ventricle. The catheter is then slightly withdrawn and rotated counterclockwise to allow for entry into the right ventricular outflow tract and main pulmonary artery. If the catheter tip becomes lodged in the right ventricular outflow tract, a soft-tipped $\mathrm{J}$ guide wire may facilitate catheter entry into the main pulmonary artery.

In patients with right atrial enlargement, the right ventricle may be difficult to probe with the standard Grollman catheter because the distal end of the catheter may be too short to allow for direct passage. In such cases, the $90^{\circ}$ angle of the distal tip may be enlarged by introducing a manually bent guide wire. The Van Aman (7 Fr APC, Cook Inc., Bloomington, IN, USA) catheter is a $7 \mathrm{Fr}$ polyurethane-modified Grollman catheter with a $90^{\circ}$ reversed secondary curve $6 \mathrm{~cm}$ (rather than $3 \mathrm{~cm}$ ) proximal to the pigtail and has been successfully used for pulmonary artery catheterization in patients with right heart enlargement.

Following successful pulmonary artery catheterization, complete pulmonary angiography with multiple views of both lungs should be obtained to identify all pulmonary vascular lesions. Small PAVMs may be missed on CT, and angiographic detection is important for planning long-term follow-up. AVMs are identified by one or more large feeding arteries and a large draining vein that opacifies before pulmonary parenchyma and the remainder of the pulmonary veins. The actual arteriovenous communication is frequently saccular or aneurysmal in appearance.

After obtaining the planning angiogram, we exchange the pulmonary angiographic catheter for the $\operatorname{Cook}{ }^{\circledR}$ White LuMax ${ }^{\circledR}$ guiding catheter, which is long enough to stabilize the system in the pulmonary artery and consists of a 7 Fr multipurpose guiding catheter and a corresponding $5 \mathrm{Fr}$ inner coaxial catheter. There is a short distal angle on both guiding and inner coaxial catheters. This guiding catheter system helps in selective embolization of PAVMs. Microcatheters can sometimes also be used coaxially through the $5 \mathrm{Fr}$ catheter if needed.

In the past, only PAVMs with feeding pulmonary arteries $3 \mathrm{~mm}$ or greater in diameter were embolized, because they were thought to be most likely to permit paradoxical emboli. In our practice, however, we embolize any PAVM that can be catheterized, because even small lesions can lead to strokes. The intended site of occlusion is the feeding artery, not the actual fistula or draining vein. After selection of the feeding artery, hand injection of contrast in multiple views maybe necessary to define the anatomy. The guiding catheter is then advanced as close to the actual shunt as possible. Occlusion of the feeding artery can be accomplished with detachable or pushable coils, or detachable plugs. We prefer to perform the embolization in the feeding artery as close as possible to the fistula using detachable coils, which have a diameter at least $20 \%$ larger than the target vessel, in order to avoid iatrogenic paradoxical emboli. If detachable coils are not available, a technique for secure placement of the first coil is to anchor the first centimeter or two of the coil in a small side branch of the feeding artery near the fistulae. As the coil is deployed, the delivery catheter is pulled into the feeding artery so that the majority of the coil is delivered in this location [Figure 7]. Additional coils or plugs more closely sized to the artery are then deposited until there is no longer filling of the shunt.

These procedures can be time-consuming, so we usually stage cases with multiple bilateral PAVMs to avoid radiation and contrast-induced complications. Our limit for radiation per session is a total air karma of 5 Gy and a total contrast load of $200 \mathrm{ml}$.

\section{Posttreatment Follow-up}

Embolization has a high technical success rate. In a recently published study, the technical success rate

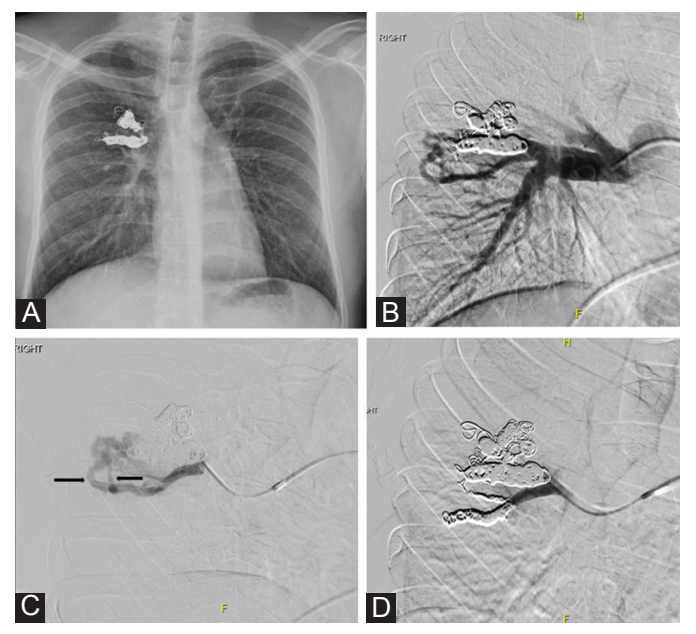

Figure 8: Recanalized complex pulmonary arteriovenous malformation. Panel A with chest X-ray demonstrating status postendovascular coil placement in pulmonary arteriovenous malformation. Panels B and C depict contrast opacification of an arteriovenous connection, consistent with recanalization of the previously embolized pulmonary arteriovenous malformation. Panel $\mathrm{C}$ demonstrates the two feeding arteries of the recanalized pulmonary arteriovenous malformation (black arrows), consistent with a complex pulmonary arteriovenous malformation. Panel D shows status post re-treatment with coil embolization of the recanalized pulmonary arteriovenous malformation. Previously visualized contrast opacification of the aneurysm is no longer seen, indicating treatment success 
was 100\%. Follow-up CT scan showed successful treatment of $97 \%$ of PAVMs. Nearly $65 \%$ of PAVMs showed complete disappearance. ${ }^{[37]}$ Other studies have shown a similar immediate technical success rate of $97 \%-100 \%$, although several embolization procedures were necessary in certain cases. ${ }^{[38,39]}$ Endovascular embolization reduces physiological shunting and prevents paradoxical embolization and hemorrhage. Despite the technical success rate, endovascular embolization has technical limitations. $8 \%-25 \%$ of the PAVM persisted postprocedurally, mostly due to recanalization. Other causes include previously untreated feeding vessels, systemic-topulmonary reperfusion, and pulmonary-to-pulmonary reperfusion. ${ }^{[40]}$ Postembolization recanalization puts patients at risk of future paradoxical embolization, even as late as 15 years postprocedure. ${ }^{[41]}$ Persistent PAVM should be treated if it becomes symptomatic (paradoxical embolization, progressive enlargement, and persistent patency of the aneurysmal sac) ${ }^{[37]}$ [Figure 8]. Technical success rate has been shown to be higher in treating recanalized PAVM as opposed to reperfused PAVM. Apart from persistent PAVM, other complications after transcatheter embolization include transient pleurisy, paradoxical device migration, and nontarget embolization. ${ }^{[23]}$ Patients should be assessed in the interventional radiology outpatient clinic after embolization. As per the 2011 guidelines, postembolization patients should undergo CT scan at 6-12 months posttranscatheter embolization and then every 3 years after. ${ }^{[24]}$ In addition, at the time of the follow-up CT scan, a dedicated assessment at the interventional radiology outpatient clinic should be warranted. $^{[42]}$

\section{Conclusion}

PAVM is a rare disease entity that creates an aberrant capillary-free arteriovenous connection. It most commonly presents in HHT patients and can result in significant morbidity. Paradoxical embolization, respiratory symptoms, and hemorrhage are common complications. Patient death is the most consequential sequelae of PAVMs, especially during pregnancy. From an imaging perspective, CT and TTCE are used to diagnose PAVM with high diagnostic yield. Angiography-guided transcatheter embolization has largely replaced surgery as the mainstay treatment option. Here, we presented the techniques employed at our institution. Endovascular treatment has a high technical success rate. However, small PAVMs will enlarge over time. Therefore, PAVM patients should be followed up closely in the interventional radiology outpatient clinic posttreatment.

\section{Financial support and sponsorship}

Nil.

\section{Conflicts of interest}

There are no conflicts of interest.

\section{References}

1. Churton T. Mutliple aneurysm of the pulmonary artery. Br Med J 1897;1:1223.

2. Nakayama M, Nawa $T$, Chonan $T$, Endo $K$, Morikawa $S$, Bando $\mathrm{M}$, et al. Prevalence of pulmonary arteriovenous malformations as estimated by low-dose thoracic CT screening. Intern Med 2012;51:1677-81.

3. Narsinh KH, Ramaswamy R, Kinney TB. Management of pulmonary arteriovenous malformations in hereditary hemorrhagic telangiectasia patients. Semin Intervent Radiol 2013;30:408-12.

4. Govani FS, Shovlin CL. Hereditary haemorrhagic telangiectasia: A clinical and scientific review. Eur J Hum Genet 2009; 17:860-71.

5. van Gent MW, Post MC, Snijder RJ, Westermann CJ, Plokker HW, Mager JJ, et al. Real prevalence of pulmonary right-to-left shunt according to genotype in patients with hereditary hemorrhagic telangiectasia: A transthoracic contrast echocardiography study. Chest 2010;138:833-9.

6. Cartin-Ceba R, Swanson KL, Krowka MJ. Pulmonary arteriovenous malformations. Chest 2013;144:1033-44.

7. Hoeper MM, Krowka MJ, Strassburg CP. Portopulmonary hypertension and hepatopulmonary syndrome. Lancet 2004;363:1461-8.

8. Dupuis-Girod S, Cottin V, Shovlin CL. The lung in hereditary hemorrhagic telangiectasia. Respiration 2017;94:315-30.

9. Bosher LH Jr., Blake DA, Byrd BR. An analysis of the pathologic anatomy of pulmonary arteriovenous aneurysms with particular reference to the applicability of local excision. Surgery 1959;45:91-104.

10. Dines DE, Seward JB, Bernatz PE. Pulmonary arteriovenous fistulas. Mayo Clin Proc 1983;58:176-81.

11. Shovlin CL, Jackson JE, Bamford KB, Jenkins IH, Benjamin $\mathrm{AR}$, Ramadan $\mathrm{H}$, et al. Primary determinants of ischaemic stroke/brain abscess risks are independent of severity of pulmonary arteriovenous malformations in hereditary haemorrhagic telangiectasia. Thorax 2008;63:259-66.

12. Santhirapala V, Williams LC, Tighe HC, Jackson JE, Shovlin CL. Arterial oxygen content is precisely maintained by graded erythrocytotic responses in settings of high/normal serum iron levels, and predicts exercise capacity: An observational study of hypoxaemic patients with pulmonary arteriovenous malformations. PLoS One 2014;9:e90777.

13. Whyte MK, Hughes JM, Jackson JE, Peters AM, Hempleman SC, Moore DP, et al. Cardiopulmonary response to exercise in patients with intrapulmonary vascular shunts. J Appl Physiol (1985) 1993;75:321-8.

14. Rozenberg D, Leek E, Faughnan ME. Prevalence and nature of dyspnea in patients with hereditary hemorrhagic telangiectasia (HHT). Respir Med 2015;109:768-77.

15. Khan AA, Hunt I, Hamdane K, Tambiah J, Deshpande RP, Reidy JF, et al. Massive pulmonary arteriovenous malformation presenting with tamponading haemothorax. Thorax 2007;62:836.

16. Kho SS, Yong MC, Chan SK, Wong MN, Tie ST. Pulmonary arteriovenous malformation presenting as spontaneous haemothorax on transthoracic ultrasound. Thorax 2018. pii: thoraxjnl-2017-211390.

17. Shovlin CL, Sodhi V, McCarthy A, Lasjaunias P, Jackson JE, Sheppard MN, et al. Estimates of maternal risks of pregnancy for women with hereditary haemorrhagic telangiectasia (Osler-weber-rendu syndrome): Suggested approach for obstetric services. BJOG 2008;115:1108-15. 
18. Kjeldsen AD, Tørring PM, Nissen H, Andersen PE. Cerebral abscesses among danish patients with hereditary haemorrhagic telangiectasia. Acta Neurol Scand 2014;129:192-7.

19. Etievant J, Si-Mohamed S, Vinurel N, Dupuis-Girod S, Decullier E, Gamondes D, et al. Pulmonary arteriovenous malformations in hereditary haemorrhagic telangiectasia: Correlations between computed tomography findings and cerebral complications. Eur Radiol 2018;28:1338-44.

20. Hsu CC, Kwan GN, Evans-Barns H, van Driel ML. Embolisation for pulmonary arteriovenous malformation. Cochrane Database Syst Rev 2018;1:CD008017.

21. Velthuis S, Buscarini E, Mager JJ, Vorselaars VM, van Gent MW, Gazzaniga $\mathrm{P}$, et al. Predicting the size of pulmonary arteriovenous malformations on chest computed tomography: A role for transthoracic contrast echocardiography. Eur Respir $\mathbf{J}$ 2014;44:150-9.

22. Vorselaars VM, Velthuis S, Snijder RJ, Westermann CJ, Vos JA, Mager JJ, et al. Follow-up of pulmonary right-to-left shunt in hereditary haemorrhagic telangiectasia. Eur Respir J 2016;47:1750-7.

23. Shovlin CL. Pulmonary arteriovenous malformations. Am J Respir Crit Care Med 2014;190:1217-28.

24. Faughnan ME, Palda VA, Garcia-Tsao G, Geisthoff UW, McDonald J, Proctor DD, et al. International guidelines for the diagnosis and management of hereditary haemorrhagic telangiectasia. J Med Genet 2011;48:73-87.

25. Goerne H, Chaturvedi A, Partovi S, Rajiah P. State-of-the-art pulmonary arterial imaging - Part 2. Vasa 2018;1-5.

26. Gill SS, Roddie ME, Shovlin CL, Jackson JE. Pulmonary arteriovenous malformations and their mimics. Clin Radiol 2015;70:96-110.

27. Ichiki Y, Kawasaki J, Hamatsu T, Suehiro T, Koike M, Tanaka F, et al. Lung granuloma mimicking pulmonary arteriovenous malformation: Report of a case. Int J Surg Case Rep 2015;6C: 154-6.

28. Chick JF, Reddy SN, Pyeritz RE, Trerotola SO. A survey of pulmonary arteriovenous malformation screening, management, and follow-up in hereditary hemorrhagic telangiectasia centers of excellence. Cardiovasc Intervent Radiol 2017;40:1003-9.

29. Tanabe Y, Landeras L, Ghandour A, Partovi S, Rajiah P. State-of-the-art pulmonary arterial imaging - Part 1. Vasa 2018;1-5.

30. Chokkappan K, Kannivelu A, Srinivasan S, Babut SB. Review of diagnostic uses of shunt fraction quantification with technetium- $99 \mathrm{~m}$ macroaggregated albumin perfusion scan as illustrated by a case of osler-weber-rendu syndrome. Ann Thorac
Med 2016;11:155-60.

31. Puskas JD, Allen MS, Moncure AC, Wain JC Jr., Hilgenberg AD, Wright $\mathrm{C}$, et al. Pulmonary arteriovenous malformations: Therapeutic options. Ann Thorac Surg 1993;56:253-7.

32. Fukushima H, Mitsuhashi $T$, Oto $T$, Sano $Y$, Kusano KF, Goto $\mathrm{K}$, et al. Successful lung transplantation in a case with diffuse pulmonary arteriovenous malformations and hereditary hemorrhagic telangiectasia. Am J Transplant 2013;13:3278-81.

33. Gossage JR, Kanj G. Pulmonary arteriovenous malformations. A state of the art review. Am J Respir Crit Care Med 1998; 158:643-61.

34. Boother EJ, Brownlow S, Tighe HC, Bamford KB, Jackson JE, Shovlin CL, et al. Cerebral abscess associated with odontogenic bacteremias, hypoxemia, and iron loading in immunocompetent patients with right-to-left shunting through pulmonary arteriovenous malformations. Clin Infect Dis 2017;65:595-603.

35. Todo K, Moriwaki H, Higashi M, Kimura K, Naritomi H. A small pulmonary arteriovenous malformation as a cause of recurrent brain embolism. AJNR Am J Neuroradiol 2004;25:428-30.

36. Andersen PE, Kjeldsen AD. Embolization of pulmonary AVMs of feeding arteries less than $3 \mathrm{~mm}$ : Reports of two cases and an 8-year follow-up without embolization. Acta Radiol Short Rep 2012;1. pii: arsr. 2012.

37. Abdel Aal AK, Ibrahim RM, Moustafa AS, Hamed MF, Saddekni S. Persistence of pulmonary arteriovenous malformations after successful embolotherapy with amplatzer vascular plug: Long-term results. Diagn Interv Radiol 2016;22:358-64.

38. White RI Jr., Lynch-Nyhan A, Terry P, Buescher PC, Farmlett EJ, Charnas L, et al. Pulmonary arteriovenous malformations: Techniques and long-term outcome of embolotherapy. Radiology 1988;169:663-9.

39. Dutton JA, Jackson JE, Hughes JM, Whyte MK, Peters AM, Ussov W, et al. Pulmonary arteriovenous malformations: Results of treatment with coil embolization in 53 patients. AJR Am J Roentgenol 1995;165:1119-25.

40. Woodward CS, Pyeritz RE, Chittams JL, Trerotola SO. Treated pulmonary arteriovenous malformations: Patterns of persistence and associated retreatment success. Radiology 2013;269:919-26.

41. Farooq S, Mowla A, Razek MA, Iqbal A, Sawyer RN. Delayed recanalization of an embolized pulmonary arteriovenous malformation caused brain abscess in a patient with OslerWeber-Rendu syndrome. Arch Neurosci 2017;44:e35607.

42. Abboud S, Partovi S, Nakamoto D, Azar N. The radiologist will see you now: Patients' perceptions of an outpatient interventional clinic. Curr Probl Diagn Radiol 2016;45:137-8. 